\title{
Aeroelasticity in Turbomachines: Some Aspects of the Effect of Coupling Modeling and Blade Material Changes*
}

\author{
FRANÇOIS MOYROUD $^{\mathrm{a}, t}$, GEORGES JACQUET-RICHARDET $^{\mathrm{a}}$ and TORSTEN H. FRANSSON ${ }^{\mathrm{b}}$ \\ 'Laboratoire de Mécanique des Structures UPRESA CNRS, INSA de Lyon, F-69100 Villeurbanne, France; \\ ${ }^{\mathrm{b}}$ Division of Heat and Power Technology, Royal Institute of Technology S-10044 Stockholm, Sweden
}

(Received 4 September 1998)

\begin{abstract}
Two methods are generally used for the aeroelastic analysis of bladed-disc assemblies. The first, often referred to as the energy method, assumes that the fluid does not modify invacuum structural dynamic behavior. On the other hand, the second, based on an eigenvalue approach, considers the feedback effect of the fluid on the structure. In this paper, these methods are compared using different test cases, in order to highlight the limitations of the energy method. Within this comparison, the effect of material modifications on the coupled behavior of the assembly is examined.
\end{abstract}

Keywords: Fluid-structure coupling, Energy method, Modal coupling method, Bladed assemblies, Effect of structural changes

\section{INTRODUCTION}

Recent technological advances allow the design of blades which are lighter, thinner and which can run at high rotation speeds. These features lead to significant improvements in terms of turbomachine performance and efficiency. However, they also increase the risks of emergence of aeroelastic problems such as flutter or forced response. Flutter is a self-excited instability resulting from aerodynamic forces induced by blade vibration. Forced response is primarily caused by rotation of the blading in non-uniform incoming flow fields. In order to fulfill the necessarily severe requirements of safety, performance and cost-effectiveness, it is essential to be able to predict the occurrences of these aeroelastic problems as soon and as precisely as possible.

At present, fluid-structure coupled analyses are mostly performed by fluid oriented specialists, working with vibrational data obtained from invacuum structural computations: Carta (1967),

\footnotetext{
* This paper was originally presented at ISROMAC-7.

${ }^{\dagger}$ Corresponding author. Tel.: 047243 8568. Fax: 047243 8930. E-mail: lmst@1mst.insa-lyon.fr.
} 
Bölcs and Fransson (1986). In this context, aeroelastic analyses are often performed using the so-called Energy Method, which ignores the feedback effect of the fluid on structural vibration. On the contrary, certain approaches are highly coupled and involve solving both structure and fluid equations in a single time marching scheme: Bendiksen (1991), He (1984), Marshall and Imregun (1995). These approaches, although very attractive, are currently far too computationally expensive for design procedures. Between these extremes, linearized frequency domain methods which include modal approaches, have played and still play an important role: Kielb and Kasa (1984), Srinivasan and Fabunmi (1984), Smith (1991), Gerolymos (1993), Jacquet-Richardet and Henry (1994), Imregun (1995), Moyroud et al. (1996). This paper first describes a modal aeroelastic analysis method adapted to turbomachinery flutter analyses. The general theoretical background is presented. Then, the characteristics of the coupling method retained are shown to allow a unified presentation of both the energy method and the modal method. In this respect, these two methods are compared on a given application. Finally, the influence of specific structural modifications is discussed.

Detailed parametric studies, as proposed for example by Bendiksen and Friedmann (1982), can be found on the subject. The main objectives of the paper are to examine the evolution of the error introduced by the energy method, when considering advanced technologies such as composite or honeycomb, and to examine the effect of possible structural changes only, without any blade outer geometry modification and taking a realistic structure into consideration.

\section{THEORETICAL BACKGROUND}

\subsection{Modal Method}

The general formulation, briefly presented here, is based on a modal approach of the linearized coupled problem. The structure is assumed to be constituted with $N$ blades mounted on a flexible disk. The displacement of such a cyclic assembly is written in terms of traveling wave coordinates. For a given traveling wave, $n$, all the sectors of the structure vibrate according to the same mode but each of them is out of phase with respect to the next by a constant phase angle $\beta_{n}$. The relationship between the physical displacement of blade $s$ and the traveling wave coordinate associated with reference blade 1 is

$$
\begin{aligned}
\delta_{s} & =\sum_{n=0}^{N} \delta_{n} \mathrm{e}^{\mathrm{j}(s-1) \beta_{n}} \quad \text { with } \\
\beta_{n} & =\frac{2 \pi n}{N} ; n=0, \ldots, N-1 .
\end{aligned}
$$

When considering tuned assemblies, blades in a row are identical and all the traveling wave modes are independent and can be calculated separately (Crawley, 1987). In this case, the dynamic behavior of the assembly is governed by

$$
\left[M_{n}\right]\left\{\ddot{\delta}_{n}\right\}+\left[C_{n}\right]\left\{\dot{\delta}_{n}\right\}+\left[K_{n}(\Omega, \bar{\delta})\right]\left\{\delta_{n}\right\}=\left\{F_{n}\right\}+\left\{F_{\mathrm{e}}\right\},
$$

where $n$ is the traveling wave order, $\delta_{n}, \dot{\delta}_{n}$ and $\ddot{\delta}_{n}$ are respectively the structural displacement, velocity and acceleration vectors, $M_{n}$ is the mass matrix, $C_{n}$ accounts for gyroscopic and damping effects and $K_{n}$ is the stiffness matrix. On the righthand side of the equation, $F_{n}$ is the vector of unsteady aerodynamic forces and $F_{\mathrm{e}}$ is the vector of all the motion independent excitation forces. Matrix $K_{n}$ includes both non-linear stress stiffening and spin softening effects induced by rotation at speed $\Omega$. This matrix is obtained after a preliminary computation of the non-linear static equilibrium position of the structure subjected to centrifugal and steady fluid forces $(\bar{\delta})$.

A direct solution of system (2) remains difficult for three main reasons. First, even when reduced to one basic cyclic sector of the assembly, the size of the system remains large for precise analyses. Second, due to unsteady aerodynamic forces the system remains non-linear. Third, since different 
discretizations and different meshes are usually used for structure and fluid, compatibility problems at the interface should be solved before any computation. As shown for example by JacquetRichardet et al. (1994) and by Moyroud et al. (1996), these drawbacks can be efficiently overcome using a linearized modal approach.

The first step of the modal method consists in solving the problem, without damping and invacuum, associated with (2). Then, assuming that the coupled vibration can be written as a linear combination of the first $m$ modes obtained $\left(\left\{\phi_{n i}\right\}\right.$, $i=1, \ldots, m)$, this results in

$$
\left\{\delta_{n}\right\}=\sum_{i=1}^{m}\left\{\phi_{n i}\right\} q_{n i}=\left[\phi_{n}\right]\left\{q_{n}\right\} .
$$

Carrying over Eq. (3) to Eq. (2) gives

$$
\left[m_{n}\right]\left\{\ddot{q}_{n}\right\}+\left[c_{n}\right]\left\{\dot{q}_{n}\right\}+\left[k_{n}\right]\left\{q_{n}\right\}=\left\{f_{n}\right\}+\left\{f_{\mathrm{e}}\right\},
$$

where

$$
\begin{aligned}
{\left[m_{n}\right] } & =\left[\phi_{n}\right]^{\mathrm{t}}\left[M_{n}\right]\left[\phi_{n}\right], \quad\left[c_{n}\right]=\left[\phi_{n}\right]^{\mathrm{t}}\left[C_{n}\right]\left[\phi_{n}\right], \\
{\left[k_{n}\right] } & =\left[\phi_{n}\right]^{\mathrm{t}}\left[K_{n}\right]\left[\phi_{n}\right], \quad\left\{f_{n}\right\}=\left[\phi_{n}\right]^{\mathrm{t}}\left\{F_{n}\right\}, \\
\left\{f_{\mathrm{e}}\right\} & =\left[\phi_{n}\right]^{\mathrm{t}}\left\{F_{\mathrm{e}}\right\} .
\end{aligned}
$$

Matrices $m_{n}$ and $k_{n}$ are diagonal. Using a linearized unsteady fluid model, motion dependent fluid forces are proportional to the vibratory displacement and, thus, can be written as

$$
\left\{f_{n}\right\}=\left[\phi_{n}\right]^{\mathrm{t}}\left\{F\left(\left[\phi_{n}\right]\left\{q_{n}\right\}\right)\right\}=\left[\phi_{n}\right]^{\mathrm{t}}\left[A_{n}\right]\left\{q_{n}\right\}=\left[a_{n}\right]\left\{q_{n}\right\} .
$$

The vectors of matrix $A_{n}$ represent the unsteady forces generated by the structure, when vibrating according to each mode shape kept in the modal basis, at the frequency of the coupled system. The order of matrix $a_{n}$ is $m$ by $m$ and this matrix is naturally a function of the aerodynamic conditions associated with the operating point considered. By assuming the standard assumption of harmonic motion and excitation, and carrying over (6) to (4), this leads to the modal aeroelastic equations in the frequency domain:

$$
\lambda_{n}^{2}\left[m_{n}\right]\left\{\bar{q}_{n}\right\}+\lambda_{n}\left[c_{n}\right]\left\{\bar{q}_{n}\right\}+\left[k_{n}-a_{n}\right]\left\{\bar{q}_{n}\right\}=\left\{f_{\mathrm{e}}\right\} .
$$

Due to the phase difference between the structural motion and the motion dependent unsteady aerodynamic forces, matrix $a_{n}$ is complex. If the excitation forces are ignored, the system reduces to a complex eigenvalue/eigenvector problem whose solution is obtained, for each mode $i$, in the form

$$
\lambda_{n i}=\lambda_{n i}^{\mathrm{R}}+\mathrm{j} \lambda_{n i}^{\mathrm{I}} .
$$

As the aeroelastic matrix $a_{n}$ is a function of vibrational characteristics of the coupled system, a few iterations are generally needed to obtain a converged solution. The values of the damped frequency $\omega_{n i}^{*}$ and of the associated damping ratio $\alpha_{n i}$ are given by analogy with the one degree of freedom systems, as follows:

$$
\omega_{n i}^{*}=\lambda_{n i}^{\mathrm{I}}, \quad \alpha_{n i}=\lambda_{n i}^{\mathrm{R}} / \sqrt{\left(\lambda_{n i}^{\mathrm{R}}\right)^{2}+\left(\lambda_{n i}^{\mathrm{I}}\right)^{2}} .
$$

The logarithmic decrement $\gamma_{n i}$ can be obtained from the damping ratio according to

$$
\gamma_{n i}=2 \pi \alpha_{n i} / \sqrt{1-\alpha_{n i}^{2}} \approx 2 \pi \alpha_{n i} .
$$

\subsection{Energy Method}

The energy method, introduced by Carta (1967), is an uncoupled approach based on the assumption that the frequency and the mode shape of the coupled system remain identical to those of the structure in a vacuum. The logarithmic decrement obtained by using the energy method is expressed by Carta as

$$
\gamma=\frac{W}{4 K},
$$

where $W$ is the work done per cycle by the aerodynamic forces and $K$ is the mean kinetic energy calculated over one cycle of vibration. 
Considering the modal method, the basic assumption of the energy method is easily accounted for by reducing the modal basis to a single natural mode, i.e. the mode under consideration. Thus (3) becomes

$$
\left\{\delta_{n}\right\}=\left\{\phi_{n i}\right\} q_{n i}
$$

In this case, the aeroelastic eigenvalue/eigenvector problem reduces to

$$
\begin{aligned}
& \lambda_{n i}^{2} m_{n i}+\lambda_{n i} c_{n i}+\left(k_{n i}-a_{n i}\right)=0, \quad \text { where } \\
& a_{n i}=\left\{\phi_{n i}\right\}^{\mathrm{t}}\left[F_{n}\left(\phi_{n i}\right)\right] .
\end{aligned}
$$

The energy method does not consider structural damping. Thus, considering the complex nature of $a_{n i}$ and $\lambda_{n i}$, the real part of the solution of Eq. (13) becomes

$$
\lambda_{n i}^{\mathrm{R}}=\alpha_{n i} \omega_{n i}=a_{n i}^{\mathrm{I}} / 2 m_{n i} \lambda_{n i}^{\mathrm{I}} \quad \text { with } \omega_{n i}^{2}=k_{n i} / m_{n i} .
$$

Assuming that natural frequency is not modified by fluid influence, (14) gives the following expression for the aerodynamic damping ratio and the associated logarithmic decrement:

$$
\alpha_{n i}=a_{n i}^{\mathrm{I}} / 2 m_{n i} \omega_{n i}^{2}, \quad \gamma_{n i}=\pi a_{n i}^{\mathrm{I}} / m_{n i} \omega_{n i}^{2} .
$$

The term $a_{n i}^{\mathrm{I}}$ is homogeneous to the work per cycle of the unsteady forces on mode $i$ (Carta, 1967; Bölcs and Fransson, 1986). The term $m_{n i} \omega_{n i}^{2}$ is proportional to the vibrational kinetic energy associated with mode $i$. Consequently, the logarithmic decrement given by (15) is really homogeneous to that given by (11).

\section{APPLICATION}

Conventional fan blades for high bypass ratio engines are characterized by a high aspect ratio, and consequently are designed with part span shrouds to minimize the risks of aeroelastic instabilities. The main disadvantage of shrouds is to reduce the overall efficiency of the stage. In this respect the development of wide chord fans, without any shroud, has permitted a significant improvement in fan efficiency. The application considers three possible configurations of a selected wide chord fan stage. A general description is given and the models used for structural and fluid domains are described briefly. The results computed for the structure in a vacuum and for the fluid-structure coupled system are presented. The differences in behavior between the three configurations considered are examined and the influence of blade material changes are highlighted. Finally, the possible evolution of the error introduced by the energy method approximations, when applied to advanced configurations such as honeycomb or composite blades, is illustrated.

\subsection{Description}

The application is based on a fan rotor made of $N=22$ wide chord blades. The outer diameter of the fan is $1.9 \mathrm{~m}$. The blade length is $0.69 \mathrm{~m}$ and its aspect ratio is 2.1 . The rotor speed considered is $\Omega=2000 \mathrm{rpm}$. Three different configurations with the same blade profile are evaluated and compared: (1) blades integrally made of titanium, (2) blades with a titanium skin and a low density honeycomb core, and (3) blades made of laminates of composite material.

The advantage of configurations 2 and 3 is to significantly reduce the weight of the assembly while maintaining good mechanical properties. The main characteristics of the three configurations are as follows: Configuration 1, Young modulus $E_{\mathrm{t}}=1.15 \times 10^{11} \mathrm{~Pa}$, density $\rho_{\mathrm{t}}=4291 \mathrm{~kg} / \mathrm{m}^{3}$ and Poisson's coefficient $\nu_{\mathrm{t}}=0.34$. For configuration 2 , the thickness of the honeycomb core is assumed to be $60 \%$ of the total thickness, with the exception of elements associated with trailing edge and leading edge completely made of titanium. The honeycomb core is modeled as an equivalent homogeneous material whose properties are: Young modulus $E_{\mathrm{h}}=1.1 \times 10^{10} \mathrm{~Pa}$, density $\rho_{\mathrm{h}}=20 \mathrm{~kg} / \mathrm{m}^{3}$. Considering configuration 3 , the blade is assumed 
to be made of laminates of graphite epoxy with the following properties: Young's modulus $E_{1}=$ $1.35 \times 10^{11} \mathrm{~Pa}$ and $E_{2}=1.00 \times 10^{10} \mathrm{~Pa}$, shear modulus $G_{12}=5.40 \times 10^{9} \mathrm{~Pa}, G_{13}=5.40 \times 10^{9} \mathrm{~Pa}$ and $G_{23}=1.50 \times 10^{9} \mathrm{~Pa}$, density $\rho=1600 \mathrm{~kg} / \mathrm{m}^{3}$ and Poisson's coefficient $\nu_{12}=0.3$. Due to the properties of the matrix and the fibers, the characteristics of graphite epoxy laminates are not isotropic. Directions 1 and 2 are respectively fiber direction and matrix direction. The blade is assumed to be constituted by 16 layers of equal thickness with the following stacking sequence: $\left[[90,+45,-45,90]_{\mathrm{s}}\right]_{\mathrm{s}}$. Fiber orientation is defined as shown in Fig. 1.

\subsection{Structure and Fluid Modeling}

The structure is modeled using a quadrangular multilayered degenerated-solid shell element with eight nodes. As shown by Chao and Reddy (1984), or by Jacquet-Richardet and Swider (1997), this element is particularly adapted to the composite blade and allows coherent modeling of the three different cases considered. As shown in Fig. 1, the

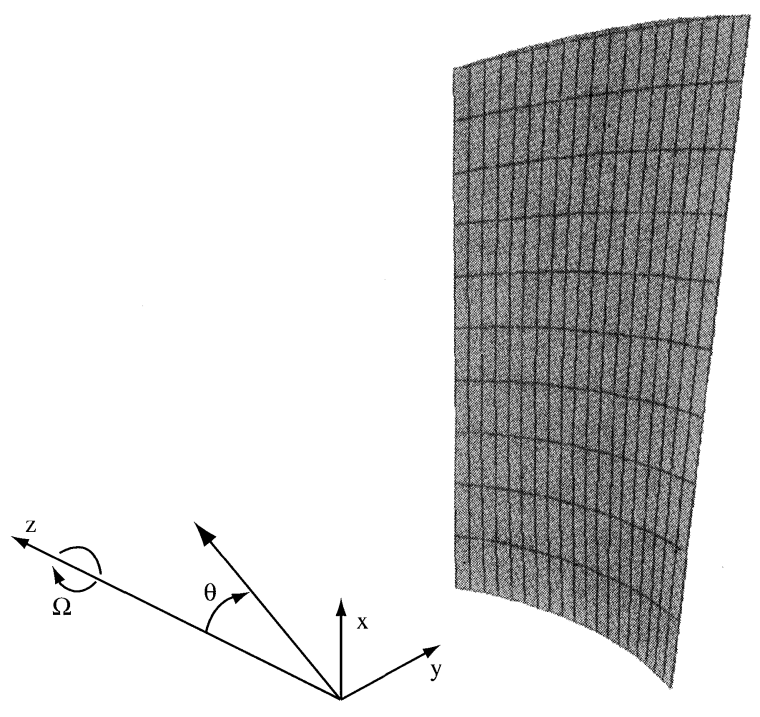

FIGURE 1 Finite element mesh. $\theta$ : fiber orientation angle of composite layers (reference: global $z$ axis). blade is meshed using 380 finite elements, resulting in 1887 nodes and 2950 degrees of freedom.

The steady and unsteady aerodynamic forces are computed using a quasi three-dimensional linearized potential flow solver, based on a Galerkin finite element discretization scheme, FINSUP Whitehead and Newton (1985) and Whitehead (1990). Although this model is based on the potential flow equations, it is believed to give reasonably accurate results for the selected subsonic-flow conditions. The eleven streamsurfaces meshed along the blade span contain about 900 two-dimensional triangular elements and 600 nodes each (Fig. 2). The inlet/outlet relative isentropic Mach number varies from $0.347 / 0.319$ at the blade's root to $0.640 /$ 0.652 at the blade's tip. The inlet/outlet relative flow incidence varies from $-27.5 / 16.9$ (root) to $-65.5 /-65.7$ (tip). For a given aeroelastic mode, the unsteady aerodynamic pressures are calculated for the 11 streamsurfaces, the 4 modes kept in the modal basis (3), and the 23 possible traveling wave orders (1).

\subsection{Dynamic Behavior of the Uncoupled System}

The first 4 natural frequencies computed for the 3 different configurations at rest are reported in

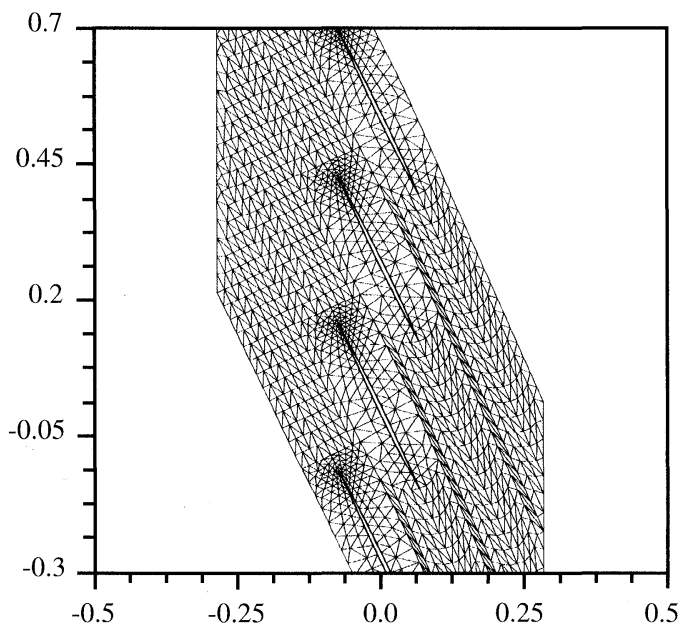

FIGURE 2 Fluid mesh - tip blade section; vertical: circumferential distance $(\mathrm{m})$ /horizontal: meridional distance $(\mathrm{m})$. 
Table I. Modes 1, 2 and 4 are flapwise bending modes while mode 3 is a torsional mode. Compared to the titanium configuration, the increase in frequency for the bending modes is about $27 \%$ for the honeycomb configuration and about $34.5 \%$ for the composite configuration. In the case of the torsional mode, this increase is limited to $15 \%$ and $27 \%$ respectively. The difference in mode shape between the three configurations is negligible - comparison performed using the modal assurance criterion proposed by Allemang and Brown (1982).

The progression of frequency with rotation speed is shown in the Campbell diagram given in Fig. 3.

TABLE I Natural frequencies; structure at rest

\begin{tabular}{lccc}
\hline Mode & $\begin{array}{c}\text { Titanium }(\mathrm{Hz}) \\
(1)\end{array}$ & $\begin{array}{c}\text { Honey comb }(\mathrm{Hz}) \\
(2)\end{array}$ & $\begin{array}{c}\text { Composite }(\mathrm{Hz}) \\
(3)\end{array}$ \\
\hline $1(1 \mathrm{~B})$ & 42.5 & 54.8 & 57.1 \\
$2(2 \mathrm{~B})$ & 131.0 & 167.2 & 178.0 \\
$3(1 \mathrm{~T})$ & 253.6 & 292.6 & 321.1 \\
$4(3 \mathrm{~B})$ & 347.8 & 433.2 & 463.8 \\
\hline
\end{tabular}

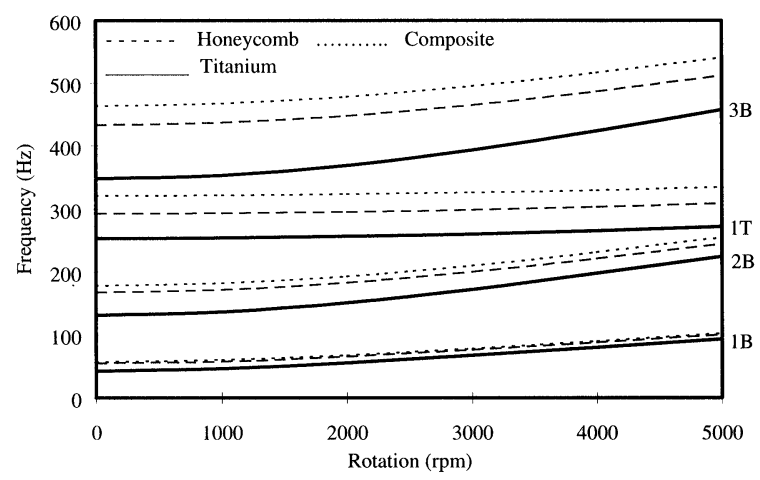

FIGURE 3 Progression of frequency with rotation: Campbell diagram.
Classically, rotation has almost no effect on torsion but it does have a considerable influence on bending. The increase in frequency is more pronounced for the titanium configuration, thus the heaviest blade. As shown in Table II for the first mode, when changing from titanium to honeycomb or composite material, the decrease in modal mass and in modal stiffness is considerable. Changes are more pronounced for the mass than for the stiffness.

\subsection{Aeroelastic Behavior of the Coupled System}

For clarity, only the results obtained for the first modes, first bendings (1B), are presented below. The reduced frequency at $80 \%$ span associated with these modes are: $k($ titanium $)=0.25$, $k($ honeycomb $)=0.29$ and $k$ (composite $)=0.30$, where $k=\omega c / 2 U$ with $\omega$ being frequency in $\mathrm{rad} / \mathrm{s}$, $c$ chord and $U$ relative inlet flow velocity in the rotating coordinate system. The unsteady pressure distribution on the blade surface is illustrated in Fig. 4. The stability loops, presented in Fig. 5, give the values of the aeroelastic damping ratio as a function of the aeroelastic frequency, for the 3 configurations and for each of the possible traveling wave orders. The system is found to be stable in all cases (negative damping ratio). From the titanium configuration to the honeycomb and composite configurations, a net increase in aeroelastic damping is observed. Damping ratios associated with composite material are more than twice those associated with titanium.

Among other parameters, Försching (1994) points out that the density of the working fluid $\rho_{\mathrm{f}}$ has a direct influence on the amount of aeroelastic damping via the mass ratio $\mu_{n i}=m_{n i} / \rho_{\mathrm{f}} c^{2}$. As the

TABLE II Modal quantities at $\Omega=2000 \mathrm{rpm}$; relative comparison between configurations 1,2 and 3

\begin{tabular}{lccccc}
\hline Mode 1B & $\begin{array}{c}\text { Titanium } \\
(1)\end{array}$ & $\begin{array}{c}\text { Honeycomb } \\
(2)\end{array}$ & $\begin{array}{c}{[(2)-(1)] /(1)} \\
(\%)\end{array}$ & $\begin{array}{c}\text { Composite } \\
(3)\end{array}$ & $\begin{array}{c}{[(3)-(1)] /(1)} \\
(\%)\end{array}$ \\
\hline Modal mass $(\mathrm{m})$ & 1.45 & 0.63 & -56 & 0.50 & -66 \\
Modal stiffness $(k)$ & $1.79 \times 10^{5}$ & $1.08 \times 10^{5}$ & -40 & $9.03 \times 10^{4}$ & -50 \\
Frequency $(\mathrm{Hz})$ & 55.8 & 65.6 & +18 & 67.7 & +21 \\
\hline
\end{tabular}



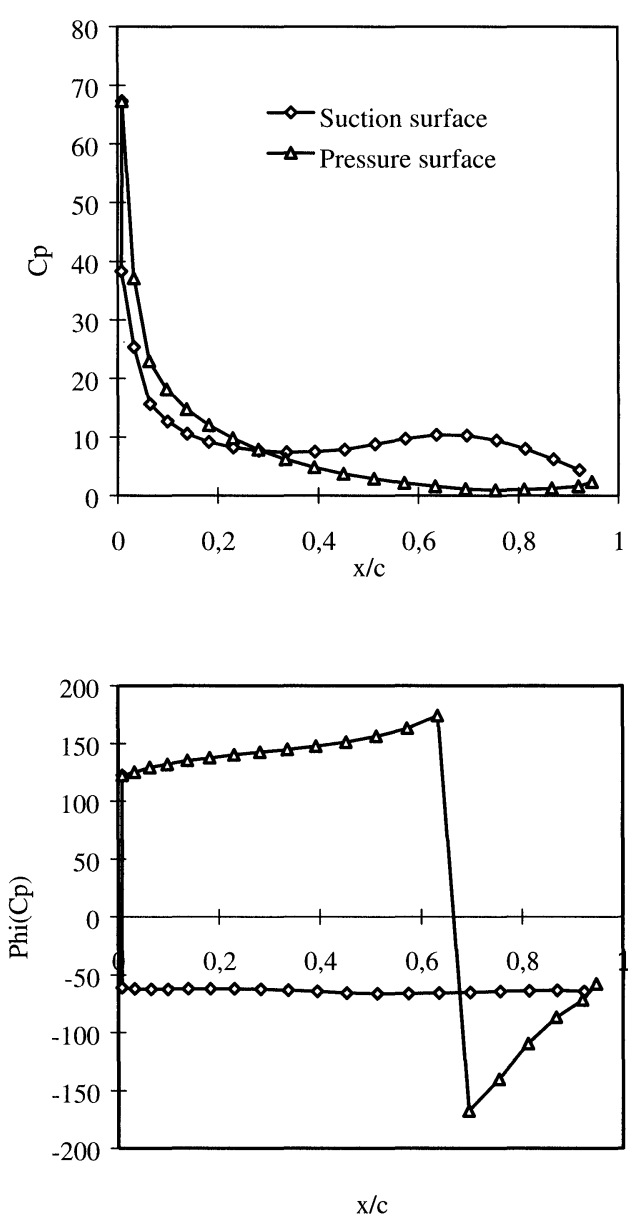

FIGURE 4 Unsteady pressure coefficients, $C_{\mathrm{p}}$ module, Phi $\left(C_{\mathrm{p}}\right)$ phase, $c$ chord, $x$ chord-wise distance. Section at $80 \%$ span, $n=12$, first mode of the composite configuration.

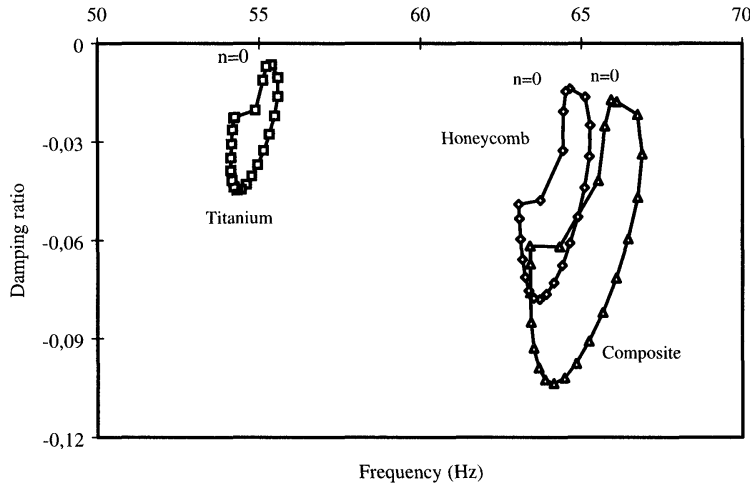

FIGURE 5 Stability loop of first bending modes. mass ratio is also directly controlled by structural density, the influence of a change in blade material is in certain cases examined in terms of mass change only. For blades entirely made of conventional materials (titanium, aluminium, steel), this criterion can be valuable since changes in material do not produce significant changes in the first natural frequencies and mode shapes. In this case, Eq. (15) confirms that the evolution of aeroelastic damping can be deduced from mass characteristics.

However, more generally, blade material changes affect both structural mass and stiffness properties. These changes lead to frequency variations and consequently unsteady aerodynamic loading variations. According to expressions (14) and (15), the ratio between the aeroelastic damping, given by two configurations $\mathrm{c} 1$ and $\mathrm{c} 2$, can be written as

$$
\frac{\gamma_{n(\mathrm{c} 1)}}{\gamma_{n(\mathrm{c} 2)}}=\frac{a_{n(\mathrm{c} 1)}^{\mathrm{I}}}{a_{n(\mathrm{c} 2)}^{\mathrm{I}}} \cdot \frac{m_{n(\mathrm{c} 2)}}{m_{n(\mathrm{c} 1)}} \cdot \frac{\omega_{n(\mathrm{c} 2)}^{2}}{\omega_{n(\mathrm{c} 1)}^{2}}=\frac{a_{n(\mathrm{c} 1)}^{\mathrm{I}}}{a_{n(\mathrm{c} 2)}^{\mathrm{I}}} \cdot \frac{k_{n(\mathrm{c} 2)}}{k_{n(\mathrm{c} 1)}}
$$

where subscript $i$, indicating the mode number, has been omitted. This ratio is an interesting tool here since mode shapes associated with the three configurations considered were found identical and normalized in the same way, allowing a direct comparison of modal quantities. Figure 6 shows the global ratio between the aeroelastic damping computed for the composite configuration (c1) and

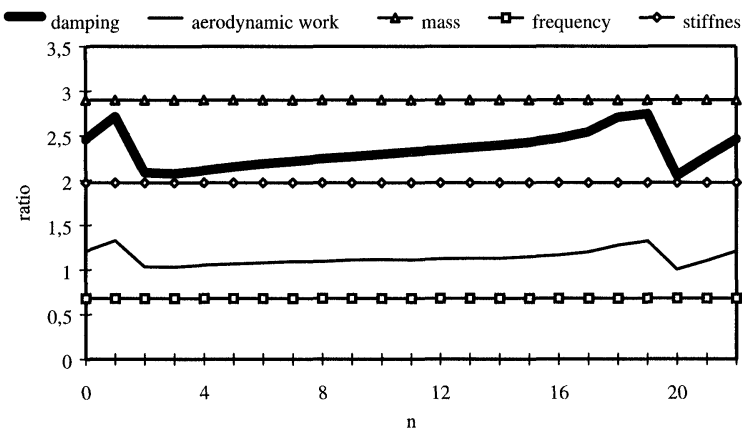

FIGURE 6 Influence of blade material changes on aeroelastic damping. (c1) composite-(c2) titanium. Damping: $\gamma_{n(\mathrm{c} 1)} / \gamma_{n(\mathrm{c} 2)}$, aerodynamic work: $a_{n(\mathrm{c} 1)}^{\mathrm{I}} / a_{n(\mathrm{c} 2)}^{\mathrm{I}}$, mass: $m_{n(\mathrm{c} 2)} /$ $m_{n(\mathrm{c} 1)}$, frequency: $\omega_{n(c 2)}^{2} / \omega_{n(\mathrm{c} 1)}^{2}$, stiffness: $k_{n(\mathrm{c} 2)} / k_{n(\mathrm{cl})}$. 
the titanium configuration (c2). The different contributions associated with unsteady aerodynamic loading, modal mass, modal stiffness and frequency changes are also reported. By examining Fig. 6, it appears clearly that aeroelastic damping changes are not governed here by a single parameter and that the different contributions have about the same level of influence on the final result. The same tendency was observed when comparing the honeycomb and titanium configurations and it should be much more pronounced when considering two composite configurations with different ply arrangements. In this case, considerable stiffness changes can be obtained without any mass modification.

\subsection{Influence of Coupling Modeling}

The energy method assumes that natural frequencies and mode shapes are not modified by unsteady aerodynamic forces. The influence of this assumption is examined here by comparison of the results computed using the modal method with 4 modes in modal basis to those directly computed using (15). This comparison is illustrated by the solid lines shown in Fig. 7, where it appears that, while not drastic the error induced by the energy method is significant. The energy method gives better results for the titanium configuration than for the composite configuration. This feature is explained by the relative stiffness of these configurations. The composite structure is less rigid and the effect of unsteady aerodynamic loading is more pronounced, leading to larger aeroelastic frequency variations.

The global error introduced by the energy method can be divided into errors associated with frequency approximation and errors associated with mode shape approximation. In order to better quantify these errors, the structure is analyzed using the modal method with only one mode in modal basis, i.e. the mode under consideration. Comparing these results to those obtained using 4 modes in modal basis gives the influence of mode shape approximation, and comparing them to those obtained using the energy method gives the influence of frequency approximation. The

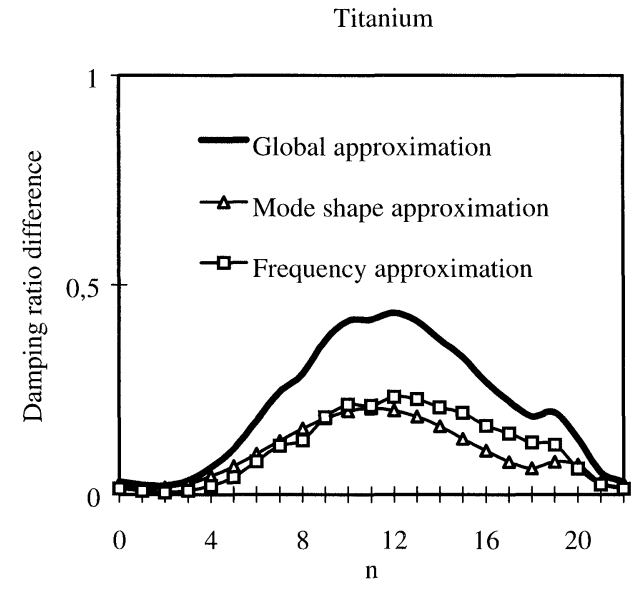

Composite

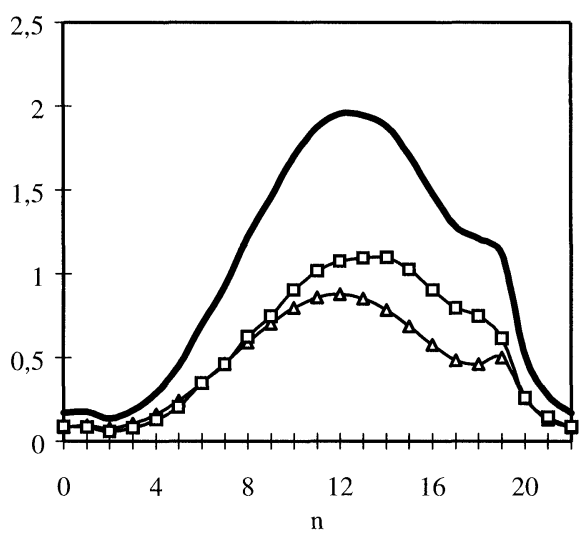

FIGURE 7 Approximation error introduced by the energy method $\left(\gamma_{n}(\right.$ ref $)-\gamma_{n}($ approx $\left.)\right)$ (note the difference in scale between the titanium and composite configurations).

examination of these partial errors, reported in Fig. 7, shows that both frequency and mode shape approximations have about the same effect.

\section{CONCLUSION}

Parametric aeroelastic studies are always of great importance but they often forget the technological feasibility hidden behind non-dimensional parameters. On the contrary, the goal of this study is to consider a realistic structural geometry and some possible configurations. Accordingly, 
although the tendencies shown should not be generalized too hurriedly, the following conclusions can be highlighted.

In the framework of fluid-structure coupled systems, the computation of the work done by the unsteady aerodynamic forces on the vibrating structure gives only information on system stability. To quantify the damping brought about by the fluid on the structure, Carta showed that it is necessary to divide this work by a term homogeneous with the kinetic energy of the mode under consideration. With such a formulation, the socalled energy method appears as a particular case of a more general and more accurate coupling method based on an eigenvalue approach (modal aeroelastic coupling method). This unified presentation is used in order to make a comparative study. The results obtained show that discrepancies induced by the energy method, although limited in the case of conventional turbomachine blades, are not inconsiderable and could be significant for advanced or critical configurations.

The effect of material modifications on the aeroelastic behavior of bladed assemblies is illustrated. Structural modifications also affect mass, stiffness and frequency characteristics. These changes have an effect on the motion dependent unsteady aerodynamic forces. Consequently, any criterion for quantifying the effect of blade material change, based on a single structural parameter, should be used with great care.

\section{Acknowledgments}

The authors gratefully acknowledge Rolls Royce plc. (England), Dr. P. Stow, for permission to use FINSUP.

\section{References}

Allemang, R.J. and Brown, D.L. (1982) A correlation coefficient for modal vector analysis, Proc. Ist Int'l. Modal Analysis Conf., Orlando.
Bendiksen, O.O. and Friedmann, P.P. (1982) The effect of bending-torsion coupling on fan and compressor blade flutter, Journal of Engineering for Power, 104, 617-623.

Bendiksen, O.O. (1991) A new approach to computational aeroelasticity, AIAA Paper 91-939-CP.

Bölcs, A. and Fransson, T.H. (1986) Aeroelasticity in turbomachines: Comparison of theoretical and experimental cascade results, Communication du LTAT no 13 EPFL Switzerland.

Carta, F.O. (1967) Coupled blade-disk-shroud flutter instabilities in turbojet engine rotor, Journal of Engineering for Power, 419-426.

Chao, W.C. and Reddy, J.N. (1984) Analysis of laminated composite shells using degenerated 3D elements, International Journal for Numerical Methods in Engineering, 20, 1991-2007.

Crawley, E.F. (1987) Aeroelastic formulation for tuned and mistuned rotors, AGARDograph no 298 Vol. 2, M.F. Platzer (ed.), pp. 19.1-19.24

Försching, H. (1994) Aeroelastic stability of cascades in turbomachinery, Progress in Aerospace Sciences, 30, 213-266.

Gerolymos, G.A. (1993) Coupled three dimensional aeroelastic stability analysis of bladed disks, Journal of Turbomachinery, 115, 791-799.

He, L. (1984) Integration of 2D fluid/structure coupled systems for calculation of turbomachinery aerodynamic/aeroelastic instabilities, Computational fluid dynamics, 3, 217-231.

Imregun, M. (1995) Prediction of flutter stability using aeroelastic frequency response functions, Journal of Fluid and Structures, 9, 419-434.

Jacquet-Richardet, G. and Henry, R. (1994) A modal aeroelastic finite element analysis method for advanced turbomachinery stages, International Journal for Numerical Methods in Engineering, 37, 4205-4217.

Jacquet-Richardet, G. and Swider, P. (1997) Influence of fibre orientation on the dynamic behaviour of rotating composite blades, Communications in Numerical Methods in Engineering, 13, $815-824$.

Kielb, R.E. and Kasa, K.R.V. (1984) Effects of structural coupling on mistuned cascade flutter and response, Journal of Engineering for Gas Turbine and Power, 106, 17-24.

Marshall, J.C. and Imregun, M. (1995) A 3D time domain flutter prediction method for turbomachinery blades, Proc. Royal Aeronautical Science Society Meeting, Manchester England.

Moyroud, F., Jacquet-Richardet, G. and Fransson, T.H. (1996) A modal coupling for fluid and structure analyses of turbomachine flutter. Application to a fan stage, ASME Paper 96-GT-335.

Smith, T.E. (1991) A modal aeroelastic analysis scheme for turbomachinery blading, NASA CR 187089.

Srinivasan, A.V. and Fabunmi, J.A. (1984) Cascade flutter analysis of cantilever blades, Journal of Engineering for Gas Turbine and Power, 106, 34-43.

Whitehead, D.S. and Newton, S.G. (1985) A finite element method for the solution of two dimensional transonic flows in cascade, International Journal for Numerical Methods in Fluids, 5, 115-132.

Whitehead, D.S. (1990) A finite element solution of unsteady two dimensional flow in cascades, International Journal for Numerical Methods in Fluids, 10, 13-34. 


\section{ait \\ ENERGY MATERIALS}

M A N E Y publishing

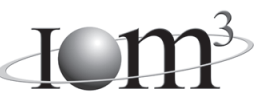

\section{Materials Science \& Engineering for Energy Systems}

Maney Publishing on behalf of the Institute of Materials, Minerals and Mining

The Institute of Materials, Minerals \& Mining

Economic and environmental factors are creating ever greater pressures for the efficient generation, transmission and use of energy. Materials developments are crucial to progress in all these areas: to innovation in design; to extending lifetime and maintenance intervals; and to successful operation in more demanding environments. Drawing together the broad community with interests in these areas, Energy Materials addresses materials needs in future energy generation, transmission, utilisation, conservation and storage. The journal covers thermal generation and gas turbines; renewable power (wind, wave, tidal, hydro, solar and geothermal); fuel cells (low and high temperature); materials issues relevant to biomass and biotechnology; nuclear power generation (fission and fusion); hydrogen generation and storage in the context of the 'hydrogen economy'; and the transmission and storage of the energy produced.

As well as publishing high-quality peer-reviewed research, Energy Materials promotes discussion of issues common to all sectors, through commissioned reviews and commentaries. The journal includes coverage of energy economics and policy, and broader social issues, since the political and legislative context influence research and investment decisions.

\section{CALL FOR PAPERS}

Contributions to the journal should be submitted online at http://ema.edmgr.com

To view the Notes for Contributors please visit: www.maney.co.uk/journals/notes/ema

Upon publication in 2006, this journal will be available via the Ingenta Connect journals service. To view free sample content online visit: www.ingentaconnect.com/content/maney

For further information please contact:

Maney Publishing UK

Tel: +44 (0)113 2497481 Fax: +44 (0)1132486983 Email: subscriptions@maney.co.uk

or

Maney Publishing North America

Tel (toll free): 8662975154 Fax: 6173546875 Email: maney@maneyusa.com

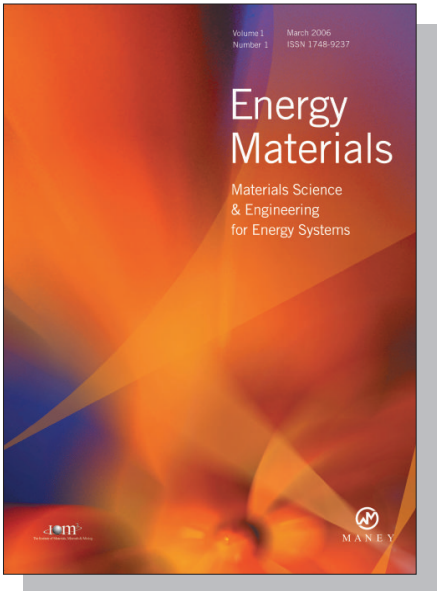

EDITORS

Dr Fujio Abe

NIMS, Japan

Dr John Hald, IPL-MPT, Technical University of Denmark, Denmark

Dr R Viswanathan, EPRI, USA

\section{SUBSCRIPTION INFORMATION}

Volume 1 (2006), 4 issues per year

Print ISSN: 1748-9237 Online ISSN: 1748-9245

Individual rate: $£ 76.00 / U S \$ 141.00$

Institutional rate: $£ 235.00 /$ US $\$ 435.00$

Online-only institutional rate: $£ 199.00 / U S \$ 367.00$

For special $\mathrm{IOM}^{3}$ member rates please email

subscriptions@maney.co.uk

\section{For further information or to subscribe online please visit www.maney.co.uk}



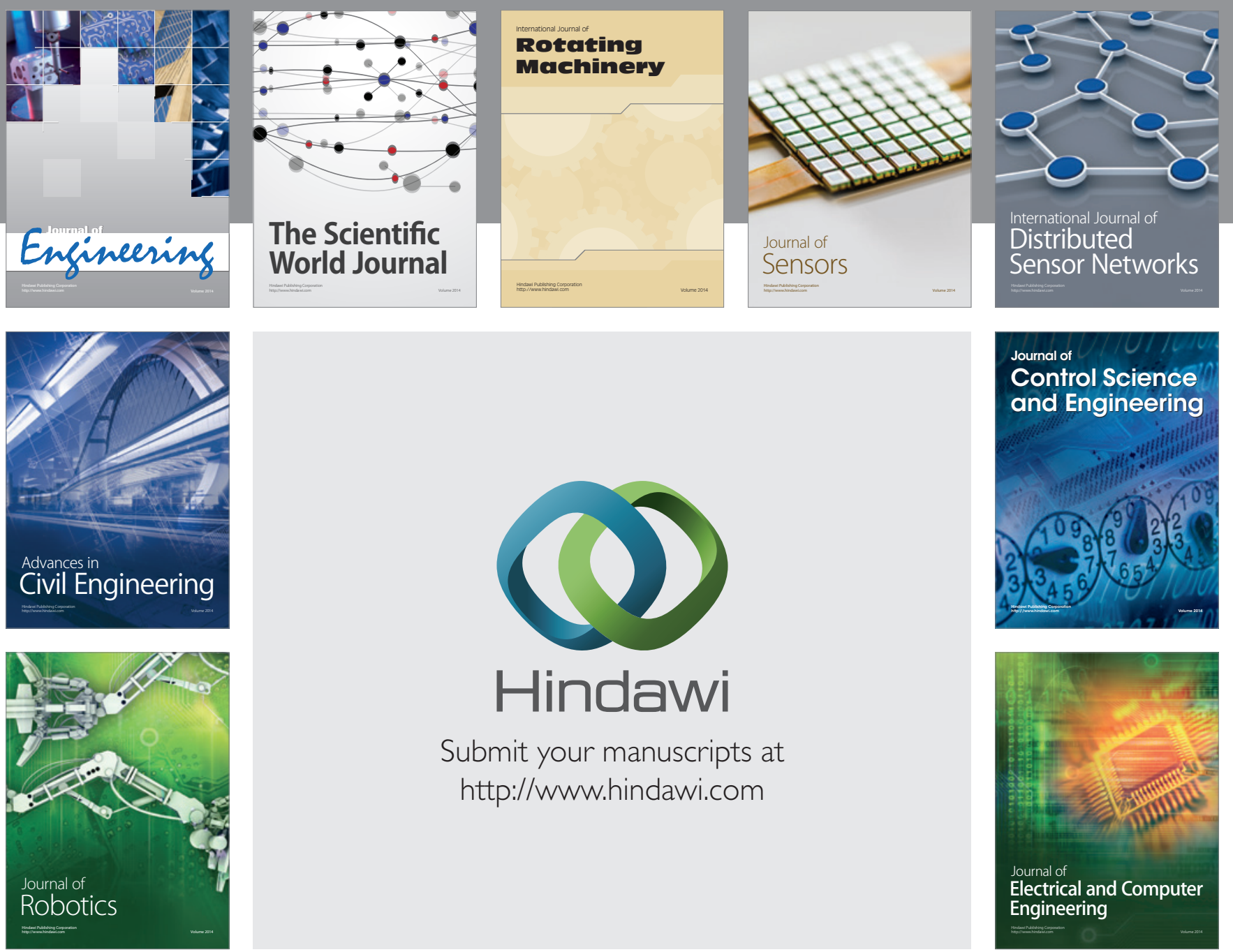

Submit your manuscripts at

http://www.hindawi.com
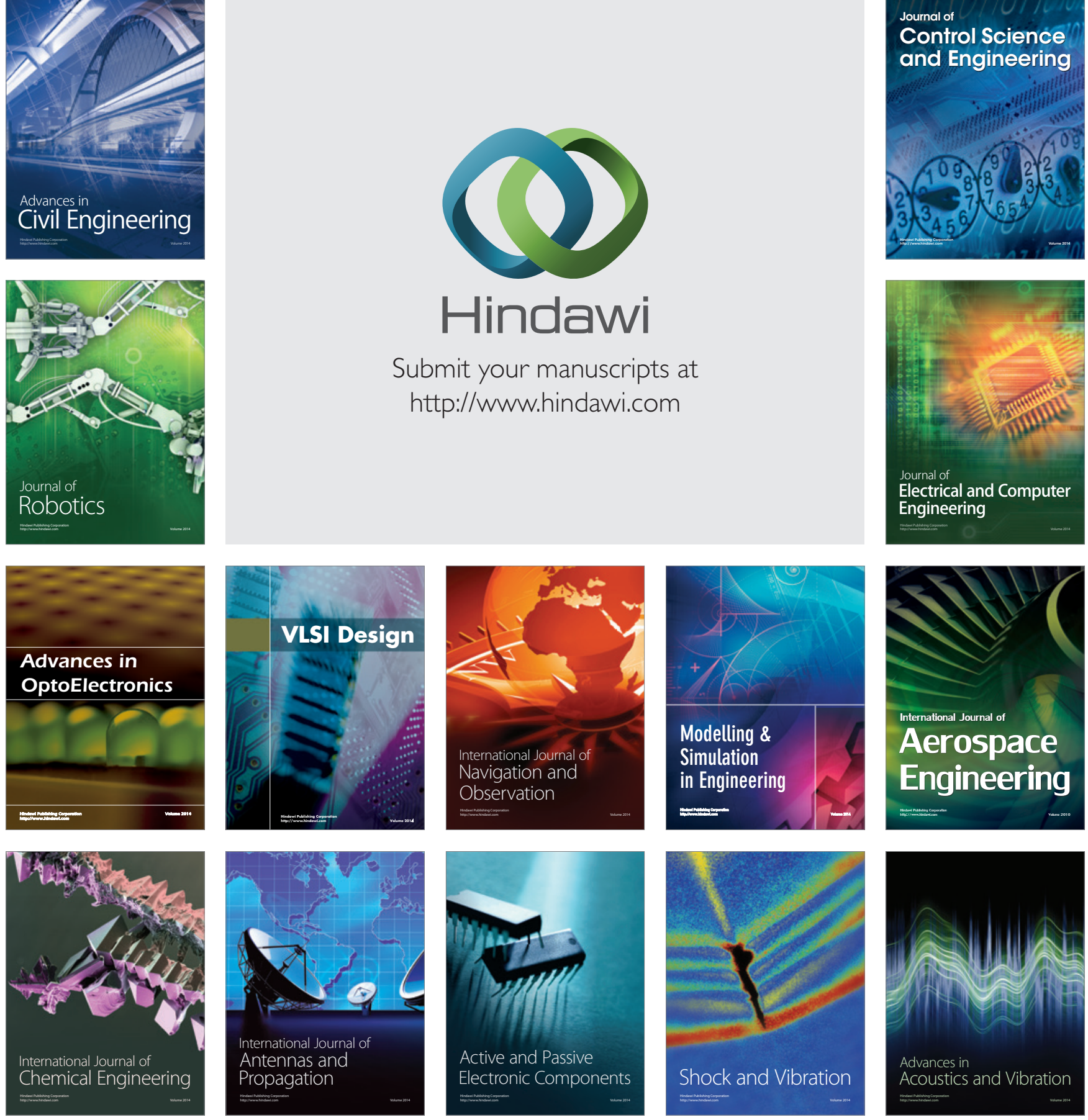